\title{
SIMMEL E O DINHEIRO: PRIMEIROS ENSAIOS
}

\author{
SIMMEL, Georg. \\ Psicologia dinheiro e outros ensaios. Tradução de Arthur \\ Morão. Lisboa: Texto e Grafia, 2009.
}

\section{POR}

\section{Natacha Simei Leal}

\begin{abstract}
graça da obra de Simmel está nos seus múltiplos temas. Inspirado pelas $A$ transformações da Berlim moderna, construiu uma trajetória intelectual 1 que se deslocou entre diversos objetos e campos de análise, o dinheiro é um deles.
\end{abstract}

Simmel é um clássico, quer por ter contribuído para a instituição da sociologia enquanto saber acadêmico legítimo, quer por ser fundador de uma forma de olhar o social. Em contraponto à perspectiva de sistema da sociologia de Durkheim, Simmel pensou a sociedade como constructo elaborado a partir de interações entre indivíduos. As relações e associações sociais, mutáveis por excelência, constantemente constituídas e dissolvidas, foram enfatizadas para compor conceitos-chaves de sua obra.

0 ensaio é marca fundante da obra simmeliana. A preocupação com os processos não poderia ser narrada na forma de reflexões duras, voltadas à composição de resultados ou dogmas. Sua escrita é aberta, descontínua e por isso infindável. Essa liberdade narrativa que torna sua obra tão instigante e original.

${ }^{1}$ Doutoranda em Antropologia Social pela Universidade de São Paulo.natachaleal@gmail.com 
Leopoldo Waizbort (2007) aponta que a obra de Simmel ganha repercussão no Brasil a partir da análise e apropriação por diversos estudiosos e escolas de ciências sociais. Defende, todavia, que sua recepção e compreensão no país passa sempre pelo filtro da "tradução da tradução", já que Simmel só escreveu em alemão.

Filosofia do dinheiro (1900) é considerado como a grande obra de Simmel. Os textos sobre o dinheiro e a vida monetária apresentados nessa coletânea são alicerces para elaborações, um tanto complexas, de Filosofia do dinheiro. Todos os ensaios, mais interessados no processo de circulação e consumo do que na produção, têm a cidade como cenário e pensam o dinheiro como resultado e símbolo de sua época.

A introdução da coletânea, escrita por Artur Mourão, organizador e tradutor dos ensaios, também merece ser mencionada. 0 filósofo português discute a hermenêutica de Simmel e argumenta que os textos sobre o dinheiro possuem diversos eixos: antropológicos, sociológicos, psicológicos, epistemológicos e também morais e espirituais. 0 esforço de Mourão é mostrar a importância de uma reflexão filosófica sobre algo aparentemente técnico e neutro.

No primeiro texto da coletânea, Psicologia do dinheiro (1890), Simmel analisa como a economia monetária organiza uma nova relação entre meios e fins. 0 dinheiro é o mediador por excelência das trocas econômicas; mas também é um fim em si mesmo, é desejado, valorizado e objetivo último (mais importante) das transações monetárias.

0 dinheiro organiza uma nova relação entre sujeitos e objetos. As trocas se dão menos em virtude das características dos objetos, e mais pelo valor econômico. Estes quando trocados, deixam de ter autenticidade e virtude, ganham sentido a partir da equivalência porque se igualam ao dinheiro. Na economia monetária o prazer está em gastar, em usufruir do dinheiro como meio de obter o maior número de coisas. Com o dinheiro o que está em jogo é menos "o que" e mais "o quanto". Tal premissa, ajuda a compor o caráter blasé de segmentos abastados da sociedade: o dinheiro, como denominador comum de inúmeras relações, permite àqueles que podem pagar mais distância e individualidade em relação a fenômenos bastante comuns.

Em Psicologia do dinheiro Simmel desenvolve uma teoria do valor subjetivista. Para 0 autor o valor não possui propriedade objetiva, é um cálculo psicológico de estimativa, um processo da vontade humana dada a partir do desejo 
de possuir. A partir dessa chave, pensa os atributos do dinheiro e seus efeitos em dimensões variadas da vida em sociedade. 0 dinheiro é desprovido de qualidades: é objetivo, abstrato, impessoal e anônimo. É incolor, não possui história e por isso é vulgar. É arquétipo dos fluxos na modernidade, circula sem cessar, mas é concomitantemente o ponto fixo a partir do qual pessoas e coisas circulam.

Em Dinheiro na cultura moderna (1896), Simmel analisa as relações do dinheiro com o indivíduo e a liberdade. Para o autor, na modernidade, a personalidade torna-se autônoma porque laços tradicionais são rompidos. Com o surgimento da economia monetária círculos pessoais se tornam mais amplos, porém menos coesos. 0 que era distante torna-se próximo porque o dinheiro é ao mesmo tempo separador e unificador de interesses.

Nesse ensaio Simmel argumenta que o dinheiro denota caráter impessoal às atividades econômicas. Há objetividade nas relações de troca, pois elas se dão de forma alheia às colaborações e ações individuais, são despersonificadas. Mas ainda que o dinheiro tenha um caráter alienador para certas relações pessoais, compõe uma série de conexões entre setores econômicos específicos. Tais relações, pautadas por valores concretos, organizam o interesse no lucro, no dinheiro como um bem em si mesmo.

0 dinheiro gera liberdade e dependência. Liberdade porque abre às pessoas um sentimento de individualidade e anonimato. Dependência porque com a divisão do trabalho, os homens produzem uns para os outros. Só o trabalho de todos organiza a unidade da economia e nivela a complexidade dos homens e das trocas. Para o autor, os objetivos dos sujeitos da modernidade são menos alcançáveis por ações imediatas do que eram nos estágios primitivos. 0 dinheiro é sempre interposto entre os homens e seus desejos. É "chave mágica”, instância de mediação porque é o acesso que nivela aquilo que originalmente é diverso e heterogêneo.

Ainda em "Dinheiro na cultura moderna" (1896), Simmel propõe uma analogia entre Deus e o dinheiro: o dinheiro é o Deus da época moderna porque é onipresente, central; é elo de reconciliação de heterogeneidades e diferenças; produz conforto psicológico porque da posse dele se obtêm paz, harmonia. Como forças abstratas, Deus e o dinheiro, superam a multiplicidade de valores e objetos, são pontos de intersecção de coisas e sentidos - por vezes antiéticas - transformadas em certezas supremas. 
Simmel trata a economia monetária como fenômeno que obedece um fluxo análogo aos demais fenômenos culturais de sua época. Em contraposição ao materialismo histórico, em que a economia é guia dos processos culturais nãoeconômicos, defende que os efeitos do dinheiro na modernidade se organizam a partir de condições psíquicas e sociais do próprio homem. Em sua análise é a relação dos homens com outros homens e dos homens com os objetos que organizam as lógicas monetárias e não-monetárias do cotidiano.

No texto de 1899, Sobre a avareza, o esbanjamento e pobreza, o autor toma a figura do avarento, do esbanjador e do miserável para construir uma teoria do valor e do dinheiro. Por caminhos distintos, tais condições trazem em si um anseio por aquilo que é ilimitado e absoluto: o dinheiro. 0 caráter abstrato do dinheiro e a distância que ele promove favorecem um contentamento objetivo, em que todos os meios e fins surgem como respostas e incentivos para adquiri-lo.

0 avarento ama o dinheiro e por isso não gasta, recusa utilizá-lo como meio de obter outros prazeres. Nesse sentido, não há nada que o dinheiro pode ocultar: nem deleites, nem desilusões. 0 dinheiro torna se um simples "poder-fazer", é desejo de um futuro alcançável e de um presente disponível. Tanto o avarento como o esbanjador reconhecem o caráter ilimitado de fruição do dinheiro. Sabem que o dinheiro é objeto capaz de adquirir todas as coisas. Mas, se para o avarento 0 prazer está em ter o dinheiro, para o esbanjador o prazer está em gastar: quer obter a constante sensação de fruição, de acesso àquilo que na aparência é ilimitado, e por vezes, infinito.

Simmel desenvolve uma teoria da troca baseada na relação entre desejo e realização. 0 valor, como processo da vontade humana, é constituído a partir de um cálculo que é incomensurável. Na equação entre desejos e realização, há uma estimativa de objetividade, um cálculo da vontade pela posse. Em contrapartida, a pobreza para o autor é a falta de acesso dos meios para o fim. Como o esbanjamento e a avareza, só é possível existir na economia monetária. Porque na economia natural, não se chega à pobreza em um sentido social, já que 0 acesso ao necessário era menos mediado. Na modernidade ela se torna ideal ético. A capacidade de constante fruição do dinheiro o torna a pior tentação, um mal genuíno, o acesso a todos os deleites mundanos. Como estratégia para salvar a alma, a pobreza, é sempre bem vista. Porque da alma se espera o mais sublime: é da renúncia ao meio, que a pobreza torna-se valor absoluto. 
Os ensaios sobre o dinheiro dessa coletânea apresentam a atualidade da teoria de Simmel. No esforço de romper com pressupostos apriorísticos, enfatizam a centralidade de aspectos relacionais da vida em sociedade.

Atento àquilo que é corriqueiro, mas não menos importante, Simmel constrói uma narrativa da modernidade, valoriza os fluxos e interações entre sujeitos, objetos e instituições. Longe das lógicas racionalistas da economia neoclássica, da centralidade da economia para o materialismo histórico e de explicações psicologizantes, elabora reflexões humanizadas das relações de troca, consumo e valor.

A coletânea Psicologia do dinheiro e outros ensaios contribui para a democratização do legado simmeliano entre leitores de língua portuguesa. Não só pela tradução desses ensaios (muito bem feita, diga-se de passagem), mas pelo cuidado de Mourão em incluir na obra uma descrição sobre a origem dos textos e uma pequena cronologia da vida de Simmel, autor que se torna indispensável para estudiosos das ciências sociais.

\section{REFERÊNCIAS}

FRÚGOLI JUNIOR, Heitor. Sociabilidade urbana. Rio de Janeiro: Jorge Zahar, 2007.

WAIZBORT, Leopoldo. Simmel no Brasil. Revista Dados, Rio de Janeiro, v. 50, n. $1,2007$. 